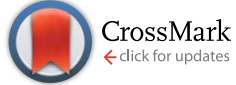

Cite this: RSC Adv., 2015, 5, 38271

Received 16th February 2015 Accepted 21st April 2015

DOI: 10.1039/c5ra02975a

www.rsc.org/advances

\section{Enzyme-catalysed regio- and enantioselective preparative scale synthesis of (S)-2-hydroxy alkanones $\dagger$}

\author{
C. Loderer and M. B. Ansorge-Schumacher* \\ $\alpha$-Hydroxy alkanones were synthesised with high enantiomeric purity by stereoselective enzyme-catalysed \\ diketone reduction. Both diketone reduction and cofactor regeneration were accomplished with purified \\ carbonyl reductase from Candida parapsilosis (CPCR2). The reaction products were isolated by column \\ chromatography and analysed by chiral GC measurements, ${ }^{1} \mathrm{H}-\mathrm{NMR}$ spectroscopy and determination of \\ optical rotations. Preparative-scale biotransformations yielded 350-600 mg of pure aliphatic $\alpha$-hydroxy \\ ketones including the difficult to obtain (S)-2-hydroxypentane-3-one. For all the products good \\ enantiomeric excesses in the range of $89-93 \%$ were achieved.
}

\section{Introduction}

Chiral $\alpha$-hydroxy ketones are important and valuable building blocks for the synthesis of several different pharmaceuticals such as anti-depressants and fungicides. ${ }^{1}$ They contain a chiral centre at the carbon atom of the hydroxy function, and in case of unequal substituents at the carbonyl and the hydroxy moiety not only enantiomers, but also structural isomers occur. Thus, synthesis of this type of compound requires regio- as well as stereoselective approaches.

Presently, various organochemical methods for the synthesis of $\alpha$-hydroxy ketones are available. Examples are ranging from peroxy acid catalysed oxidations ${ }^{2}$ to metal catalysed diketone reductions applying zinc ${ }^{3}$ or titan iodide. ${ }^{4}$ Some catalysts, such as transition metal complexes, exhibit a notable regio- and stereoselectivity, mostly, however, restricted to phenylsubstituted hydroxy ketones. ${ }^{5-11}$ Linear aliphatic $\alpha$-hydroxy ketones comprise particularly challenging targets due to the structural similarity of the substituents.

In recent years, different biocatalytic approaches for the production of $\alpha$-hydroxy ketones have been introduced as alternatives to chemical methods, including the use of isolated enzymes such as lipases, lyases, and oxidoreductases. ${ }^{\mathbf{1 , 1 2 , 1 3}}$ Lyases have been successfully applied in the synthesis of symmetric $\alpha$-hydroxy ketones such as acetoin ${ }^{\mathbf{1 4}}$ and propioin. ${ }^{15-17}$ Utilizing a lyase and decarboxylase in cascade, some non-symmetric compounds could also be synthesized. ${ }^{18}$ With lipases, kinetic resolutions of esters were conducted yielding enantiopure aliphatic $\alpha$-hydroxy ketones especially for larger

Chair of Molecular Biotechnology, Institute of Microbiology, Technische Universität Dresden, Germany. E-mail: marion.ansorge@tu-dresden.de

$\dagger$ Electronic supplementary information (ESI) available. See DOI: 10.1039/c5ra02975a substituents. ${ }^{19}$ The application of alcohol dehydrogenases for the synthesis of aliphatic $\alpha$-hydroxy ketones by means of diol oxidation $^{\mathbf{2 0 , 2 1}}$ or diketone reduction, ${ }^{21-23}$ was demonstrated. In these enzymatic processes enantiomeric excesses between 90 and 99\% were achieved. If determined, isolated yields ranged between 23 and 70\%. However, especially the diketone reduction has not been sufficiently exploited for efficient preparation of $\alpha$-hydroxy ketones so far. ${ }^{1}$

Here, we demonstrate the application of a carbonyl reductase from Candida parapsilosis CPCR2 (ref. 24-27) for the highly selective asymmetric reduction of prochiral linear aliphatic diketones to a set of corresponding $(S)$-configured $\boldsymbol{\alpha}$-hydroxy ketones in preparative scale. At the same time, the required cofactor nicotinamide adenine dinucleotide (NADH) was efficiently regenerated by oxidation of isopropyl alcohol with CPCR2 (Fig. 1). The reaction products were purified by silica gel chromatography and analysed via gas chromatography, ${ }^{1} \mathrm{H}-\mathrm{NMR}$ spectroscopy and determination of optical rotation.

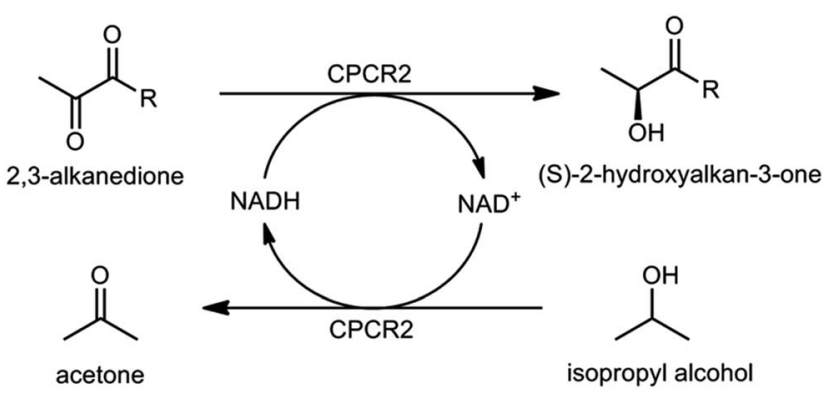

Fig. 1 Reduction of 2,3-alkanedione substrates to the corresponding (S)-2-hydroxy alkan-(3)-ones catalysed by CPCR2. Cofactor regeneration is achieved by oxidation of the co-substrate isopropyl alcohol to acetone, also catalysed by CPCR2. 
The absolute configuration was determined via ${ }^{1} \mathrm{H}-\mathrm{NMR}$ analysis of Mosher's esters obtained from the reaction products.

\section{Results and discussion}

For $\alpha$-diketone substrates with varying structural determinants and therefore varying potential for reduction by CPCR2, the specific catalytic activity of the enzyme was investigated. A selection of results is shown in Table 1 . It was found that cyclic diketones were not accepted at all, and substrates with substituents larger than a methyl group next to both carbonyl functions were converted with only low reaction rates. Aliphatic diketones comprising one methyl group next to the carbonyl functions, on the other hand, were converted with reaction rates up to $10 \mathrm{U} \mathrm{mg}^{-1}$, which is quite good. Accordingly, 2,3-alkanedione substrates were investigated for biotransformation in preparative scale.

Preparative-scale biotransformations were successfully conducted for 2,3-pentanedione, 2,3-hexanedione, and 2,3-heptanedione (entries 1a, 2a and 3a, respectively, in Table 1). Conversions between 88 and $97 \%$ were observed within only 30 minutes (Fig. 2). The yields after $1 \mathrm{~h}$ of reaction time ranged between 70 and $87 \%$. Next to the formation of the main $(S)$-product very small amounts of the $(R)$-product were detected, leading to decent enantiomeric excesses (ee-values) (Table 2 ). Taking both chiral products into account the mass balance of the reactions is imbalanced by $7-19 \%$ on the product side. This divergence between the measured decrease of substrate and increase of product may be explained by the substrate evaporation and adsorption to the reaction vessel, and a lightinduced side-reaction of diketones as described by Mäkinen and co-workers. ${ }^{28}$

After completion of the reaction after one hour, the reactants were retrieved by a four-fold extraction with equal volumes of ethyl acetate. Purification of the reaction products by column chromatography yielded highly pure fractions of the 2-hydroxyalkan-3-ones. After solvent removal ${ }^{1} \mathrm{H}$-NMR analysis was conducted showing no major impurities in the reaction products (ESI, Fig. S4-S6 $\dagger$ ). Hence, for the investigated group of substrates, the reaction is chemoselective regarding the reduction of diketones to hydroxy ketones, and regioselective regarding the carbonyl function on $\mathrm{C} 2$-position. In addition, the reaction is stereoselective, yielding ee-values between 89 and 95\% (Table 2). A significant effect of the reaction parameters temperature, $\mathrm{pH}$-value and cosubstrate concentration was not observed (Fig. S7†).

Table 1 Specific catalytic activity of CPCR2 in the reduction of diketones
Substrate

2,3-Pentanedione (1a)

2,3-Hexanedione (2a)

2,3-Heptanedione (3a)

3,4-Hexanedione

1,2-Cyclohexane-dione
Spec. activity $\left[\mathrm{U} \mathrm{mg}^{-1}\right]$

$10.0 \pm 0.3$

$8.9 \pm 0.2$

$9.1 \pm 0.1$

$1.7 \pm 0.1$

$0.0 \pm 0.0$
Performance of cofactor regeneration by using isopropyl alcohol as co-substrate effectively supplied the reaction with reduced cofactor. Turnover numbers (TONs) of NADH were 300450 (Table 3), which is a reasonable range. Improvement would certainly be possible by decreasing NADH concentration, but most probably at the cost of reaction rates. The TON of the enzyme was in the order of 105, which is excellent and a good measure for the efficiency of the catalyst. ${ }^{29}$ The procedure yielded 360-600 $\mathrm{mg}$ of the pure $(S)$ - $\alpha$-hydroxy ketones, corresponding to isolated yields between $36-46 \%$. On the one hand, these low values may be explained by the factors already discussed for the reaction yield. On the other hand the purification of the products by silica gel chromatography was not optimized and specifically difficult for the short hydrophilic substrates. Nevertheless, high space time yields (STY) between 43 and $72 \mathrm{~g}$ 
Table 2 Conversion, reaction yield, enantiomeric excess and isolated yield of 2,3-alkanedione reduction with CPCR2 on a preparative scale

\begin{tabular}{lllllll}
\hline Entry & Product & Conversion $^{a}[\%]$ & Reaction yield $^{b}[\%]$ & ee [\%] & Yield [mg] & Isolated yield [\%]
\end{tabular}

$1 \mathbf{b}$<smiles>CCC(=O)[C@@H](C)O</smiles><smiles>CCCC(=O)[C@H](C)O</smiles>

$89.5 \pm 0.1$

3b<smiles>CCCCC(=O)[C@H](C)O</smiles>

$97.1 \pm 0.2$

$97.7 \pm 0.1$

$75.5 \pm 1.2$

$87.0 \pm 0.5$

$$
75.5 \pm 1.2
$$

$2 \mathbf{b}$
$94.8 \pm 1.2$

362

$93.5 \pm 1.3$

529

46.3

601

46.9

${ }^{a}$ Substrate consumption after $1 \mathrm{~h}$, measured via GC. ${ }^{b}$ Product concentration after $1 \mathrm{~h}$, measured via GC.

per L per day were achieved (Table 3), mainly due to the fast conversion of substrates.

For determination of the absolute configuration of the main products, Mosher's esters of the reaction products were synthesised and analysed via ${ }^{1} \mathrm{H}-\mathrm{NMR} .{ }^{30}$ This method is based on an anisotropic effect of a phenyl group in the derivatization agent MTPA on the chemical shift of the protons in the substituents of a target hydroxyl compound. Both, the $(R)$ - and $(S)$-MTPA esters of each reaction product were synthesized and ${ }^{1} \mathrm{H}$-NMR spectra were recorded. The differences between the chemical shifts for protons, in the same position in both esters, are descried as $\Delta \delta$ values. For all reaction products, these $\Delta \delta$ values could only be determined for the protons on C1-position, ranging between -0.05 and $-0.06 \mathrm{ppm}$ (Table 4). Considering the spatial position of the MTPA-phenyl group, the position of the small substituent relative to the large substituent could be determined, yielding $(S)$-configuration at the hydroxy group. ${ }^{30}$ Results of the analysis are illustrated in the ESI (Fig. S8-S10 †).

The optical rotation of the reaction products was measured applying the conditions described by Martre and coworkers $\left([\alpha]_{\mathrm{D}}^{25}(c=0.9 \text {, chloroform })^{11}\right)$. With $+43.8^{\circ}$ the optical rotation of $(S)$-2-hydroxy-pentane-(3)-one is in good agreement with $+48^{\circ}$, determined in the reference study ${ }^{\mathbf{1 1}}$ (Table 4 ). With $+52.0^{\circ}$ for

Table 3 Process relevant data from preparative scale biotransformations of diketones to the corresponding chiral $\alpha$-hydroxy ketones. Turnover numbers (TON) for biocatalyst and cofactor, and space time yield (STY) of the reaction

\begin{tabular}{llll}
\hline Product & TON NADH & TON CPCR2 & STY [g per L per day] \\
\hline 1b & 297 & $2.8 \times 10^{5}$ & 43 \\
2b & 447 & $4.2 \times 10^{5}$ & 64 \\
3b & 351 & $3.3 \times 10^{5}$ & 72
\end{tabular}

(S)-2-hydroxy-hexane-(3)-one and $+59.2^{\circ}(S)$-2-hydroxy-heptane(3)-one, the reaction products exhibited increasing optical rotations with increasing size of the large substituent. For $(S)$-2-hydroxy-hexane-(3)-one the measurement was repeated under the conditions applied by Bortolini and coworkers $\left([\alpha]_{\mathrm{D}}^{20}\right.$ $\left.(c=2.5 \text {, chloroform })^{23}\right)$ The measured value of $+55.2^{\circ}$ is in good agreement with the reference $\left(57^{\circ}\right.$ (ref. 23)). In case of $(S)$-2-hydroxy-heptane-(3)-one, no reference value was detected. Thus, where available, the measured optical rotations were comparable to literature, with a tendency to lower values. This may be explained by enantiomeric impurities resulting from the biotransformation.

Summarising, the asymmetric reduction of three different 2,3-alkanediones with CPCR2 yielded the corresponding $(S)$-2-hydroxy-alkane-3-ones with good enantiomeric excesses. Due to a considerably small substrate binding pocket, ${ }^{25}$ the substrate specificity of CPCR2 restricts its application to compounds with a carbonyl group on C2-position, which on the other hand allows a highly regioselective reduction of asymmetric diketones. In addition, no consecutive reduction of the hydroxy ketone to the corresponding diol was observed as

Table 4 Chemical shifts and $\Delta \delta^{S R}$ values (in ppm) for hydrogen atoms at C1-position of hydroxy ketones and corresponding Mosher's esters

\begin{tabular}{|c|c|c|c|c|c|}
\hline Product & $\begin{array}{l}\text { Hydroxy } \\
\text { ketone }\end{array}$ & $(R)$-Ester & $(S)$-Ester & $\Delta \delta^{S R}$ & $\begin{array}{l}\text { Optical } \\
\text { rotation }\end{array}$ \\
\hline $1 b$ & 1.34 & 1.43 & 1.49 & -0.06 & $+43.8^{\circ} \pm 1.3^{a}$ \\
\hline $2 \mathbf{b}$ & 1.34 & 1.43 & 1.48 & -0.05 & $\begin{array}{l}+52.0^{\circ} \pm 1.3^{a} / \\
+55.2^{\circ} \pm 2.5^{b}\end{array}$ \\
\hline $3 \mathbf{b}$ & 1.34 & 1.43 & 1.49 & -0.05 & $+59.2^{\circ} \pm 1.9^{a}$ \\
\hline
\end{tabular}


described in previous studies with ADHs. ${ }^{\mathbf{2 0 , 2 1}}$ Here again the limitation of the substrate scope of the enzyme is turned into an advantage since the reaction selectively stops at the hydroxy ketone level. Thus, low molecular weight $\alpha$-hydroxy ketones, containing the hydroxy function on C2-position, may be synthesised chemo-, regio- and stereoselectively utilising CPCR2.

In contrast, the application of lipases for the synthesis of aliphatic hydroxy ketones shows improving enantiomeric excesses with an increasing size of both substituents. ${ }^{19}$ This is also true for lyases, where symmetric $\alpha$-hydroxy ketones with C5-substitutents were synthesized with the highest enantiomeric excesses. ${ }^{17}$ Thus, the comparably small substrate scope of the asymmetric diketone reduction with CPCR2 is compensated by the fact that the products obtained in this study are difficult to synthesize applying other enzymatic approaches.

\section{Experimental section}

If not stated otherwise all chemicals were purchased from Sigma-Aldrich (St. Louis, USA). All reactions were performed in aqueous solution.

\section{Enzyme preparation and characterization}

CPCR2 was prepared according to a modified protocol of Jakoblinnert et $a l .{ }^{27}$ Fermentation was performed in $1 \mathrm{~L}$ scale in LB medium with ampicillin $\left(100 \mu \mathrm{g} \mathrm{mL}^{-1}\right)$ in a stirred tank reactor (Biostat B Plus, Sartorius, Germany). The medium was inoculated from a preculture of $E$. coli BL21 (DE3) containing the plasmid pET22b(+):CPCR2 to a final $\mathrm{OD}_{600}$ of 0.1 . Temperature $\left(37^{\circ} \mathrm{C}\right), \mathrm{pH}(7.0)$ and dissolved oxygen (50\%) were controlled automatically. After reaching an $\mathrm{OD}_{600}$ of 0.8 , the temperature was reduced to $20{ }^{\circ} \mathrm{C}$ and protein expression was induced with IPTG (isopropyl $\beta$-D-1-thiogalactopyranoside) at a final concentration of $0.1 \mathrm{mmol} \mathrm{L}^{-1}$. After 4 hours incubation, cells were harvested by centrifugation $\left(10 \mathrm{~min}, 5000 \mathrm{~g}, 4{ }^{\circ} \mathrm{C}\right)$.

For cell lysis, the cell pellet was resuspended in $30 \mathrm{~mL}$ triethanolamine (TEA) buffer $\left(100 \mathrm{mmol} \mathrm{L}^{-1}, \mathrm{pH}=8.0\right)$ adding $50 \mu \mathrm{g} \mathrm{mL}^{-1}$ DNaseI (Applichem GmbH, Germany), $500 \mu \mathrm{g} \mathrm{mL}$ lysozyme and $1 \mathrm{mmol} \mathrm{\textrm {L } ^ { - 1 }}$ phenylmethylsulfonyl fluoride (PMSF). The lysate was cleared by centrifugation $(20 \mathrm{~min}$, $\left.16000 g, 4{ }^{\circ} \mathrm{C}\right)$. CPCR2 was purified by StrepTag affinity chromatography applying a fast protein liquid chromatography system (Äkta 920, General Electrics, USA) equipped with a $5 \mathrm{~mL}$ StrepTrap ${ }^{\circledR}$ column (General Electrics, USA) according to modified manufacturer's instructions. As washing buffer, a TEA buffer $\left(100 \mathrm{mmol} \mathrm{L}^{-1}, \mathrm{pH}=8.5\right)$ with $500 \mathrm{mmol} \mathrm{L}^{-1}$ sodium chloride, $10 \%$ (v/v) glycerol, and $1 \mathrm{mmol} \mathrm{L}^{-1}$ ethylene diamine tetra acetic acid (EDTA) was applied. For elution a TEA buffer $\left(100 \mathrm{mmol} \mathrm{L}^{-1}, \mathrm{pH}=8.5\right)$ with $500 \mathrm{mmol} \mathrm{L}^{-1} \mathrm{NaCl}, 10 \%(\mathrm{v} / \mathrm{v})$ glycerol, and $2.5 \mathrm{mmol} \mathrm{L}^{-1}$ desthiobiotin was used.

CPCR2 concentration for determination of specific activities was quantified via BCA-assay (Pierce, USA) according to the manufacturer's instructions. Enzyme activity assays were performed at $25{ }^{\circ} \mathrm{C}$ with $6.2 \mu \mathrm{g} \mathrm{mL}{ }^{-1}$ CPCR2 in $1 \mathrm{~mL}$ TEA buffer (100 $\mathrm{mmol} \mathrm{L}^{-1}$, pH 7.3) applying $3 \mathrm{mmol} \mathrm{L}^{-1}$ substrate. Reactions were started by addition of nicotinamide adenine dinucleotide $(\mathrm{NADH})$ to a final concentration of $250 \mu \mathrm{mol} \mathrm{L}{ }^{-1}$. For all substrates the initial reaction rate was measured photometrically at $340 \mathrm{~nm}$ for 2 minutes. Measurements were performed in triplicates.

For determination of stereoselectivity, activity assays were performed on $500 \mu \mathrm{L}$-scale. The reaction mixture, containing $25 \mathrm{mmol} \mathrm{L}^{-1}$ of substrate (1(a): $480 \mathrm{ng}, 2(\mathbf{a}): 533 \mathrm{ng}, 3(\mathbf{a})$ : $590 \mathrm{ng}$ ), $250 \mu \mathrm{mol} \mathrm{L}{ }^{-1} \mathrm{NADH}, 5 \%$ (v/v) isopropyl alcohol and $4 \mathrm{mmol} \mathrm{L}{ }^{-1}$ dithiothreitol (DDT) in TEA buffer $\left(100 \mathrm{mmol} \mathrm{L}^{-1}\right.$, $\mathrm{pH}$ 7.3), was prepared and preincubated at $25{ }^{\circ} \mathrm{C}$ for $5 \mathrm{~min}$. Conversion was started by addition of $1 \mu \mathrm{g} \mathrm{mL}{ }^{-1}$ CPCR2. Reactions were performed at room temperature in a shaker (Vibramax 110, Heidolph, Germany) at $1000 \mathrm{rpm}$ for $30 \mathrm{~min}$. $125 \mu \mathrm{L}$ samples were withdrawn every $10 \mathrm{~min}$ and extracted with $125 \mu \mathrm{L}$ ethyl acetate. Product concentrations were determined via chiral GC.

\section{Preparative biotransformation}

Preparative biotransformations were conducted in $200 \mathrm{~mL}$-scale in $500 \mathrm{~mL}$ shake-flasks mixed with a magnetic stir bar (80 rpm) at room temperature. The reaction mixture contained: CPCR2 $8.5 \mu \mathrm{g} \mathrm{mL} \mathrm{mL}^{-1}$, substrate $50 \mathrm{mmol} \mathrm{L}^{-1}$ (1(a): $961 \mathrm{mg}, 2$ (a): $1066 \mathrm{mg}, 3(\mathrm{a}): 1179 \mathrm{mg}$ ), NADH $100 \mu \mathrm{mol} \mathrm{L}^{-1}$, isopropyl alcohol $5 \%(\mathrm{v} / \mathrm{v})$, TEA (100 mmol L $\left.{ }^{-1}, \mathrm{pH} 7.3\right)$, dithiothreitol (DDT) $4 \mathrm{mmol} \mathrm{L}^{-1}$. Like for activity assays isopropyl alcohol acts as cosubstrate for cofactor regeneration. $5 \%(\mathrm{v} / \mathrm{v})$ isopropyl alcohol corresponds to a concentration of $650 \mathrm{mmol} \mathrm{L}^{-1}$ yielding a 13-fold excess of cosubstrate over the substrate. All components except for CPCR2 were premixed under the given conditions until the substrate was dissolved completely. Then the reaction was initiated by the addition of CPCR2. The biotransformations were stirred for one hour and samples were withdrawn at definite time intervals (15 min) and extracted with one sample volume of ethyl acetate. Conversion of substrates and synthesis of products was assessed by GC.

\section{Product purification and analytics}

Reaction products were isolated by four consecutive extractions with $200 \mathrm{~mL}$ of ethyl acetate. Purification was performed via column chromatography using silica gel 60 (Sigma Aldrich, Germany) as solid phase and a solvent mixture of $n$-hexane and ethyl acetate at a ratio of $4: 1$ (compounds 2,3) and $1: 1$ (compound 1), respectively. Purification was monitored via GC and thin layer chromatography (TLC) in combination with cerium sulfate staining.

GC analysis of the reaction products was performed on a Shimadzu GC2010 gas chromatograph with flame ionization detector (FID) and an AOC20i Autosampler. For separation of all chiral compounds Hydrodex $\gamma$ DIMOM (Macherey-Nagel, Germany) was applied as solid phase using different temperature gradients for each compound. The carrier gas $\mathrm{N}_{2}$ was applied with a pressure of $70 \mathrm{kPa} .2 \mu \mathrm{L}$ of the extracted samples were injected to the column without split flow. Exemplary chromatograms are provided in the ESI (Fig. S1-S3†).

2,3-Pentanedione. A temperature gradient from $95-115{ }^{\circ} \mathrm{C}$ was applied with a ramp of $2{ }^{\circ} \mathrm{C} \min ^{-1}$. Retention times were 
determined at $3.3 \mathrm{~min}$ for 2,3-pentanedione 1(a), $5.6 \mathrm{~min}$ for $(R)$-2-hydroxy-pentan-(3)-one and $7.8 \mathrm{~min}$ for $(S)$-2-hydroxypentan-(3)-one 1(b) (ESI, Fig. S1†).

2,3-Hexanedione. A temperature gradient from $98-122{ }^{\circ} \mathrm{C}$ was applied with a ramp of $2{ }^{\circ} \mathrm{C} \min ^{-1}$. Retention times were determined at $3.8 \mathrm{~min}$ for 2,3-hexanedione 2(a), $8.6 \mathrm{~min}$ for $(R)$-2-hydroxy-hexan-(3)-one and $9.2 \mathrm{~min}$ for $(S)$-2-hydroxyhexan-(3)-one 2(b) (ESI, Fig. S2 $\dagger$ ).

2,3-Heptanedione. A temperature gradient from $105-125{ }^{\circ} \mathrm{C}$ was applied with a ramp of $2{ }^{\circ} \mathrm{C} \mathrm{min}^{-1}$. Retention times were determined at $4.4 \mathrm{~min}$ for 2,3-heptanedione 2(a), $9.1 \mathrm{~min}$ for $(R)$-2-hydroxy-heptan-(3)-one and $9.4 \mathrm{~min}$ for $(S)$-2-hydroxyheptan-(3)-one 2(b) (ESI, Fig. S3†).

Reaction products were identified via ${ }^{1} \mathrm{H}-\mathrm{NMR}$ spectroscopy (500 MHz, Bruker DRX-500) using chloroform-d $\left({ }^{1} \mathrm{H}: \delta\right.$ 7.26). ${ }^{1} \mathrm{H}$-NMR spectra are provided in the ESI (Fig. S4-S6†).

$(S)$-2-Hydroxy-pentan-3-one $(\mathbf{1 b}):[\alpha]_{\mathrm{D}}^{25}=+43.8^{\circ} \pm 1.3(c=0.9$, chloroform) yellowish oil, ( $\left.{ }^{1} \mathrm{H}-\mathrm{NMR}, 500 \mathrm{MHz}\right) \delta$ (ppm): 4.19 (1H, q, $j=7.08, \mathrm{CH}-\mathrm{OH}), 3.40$ (1H, bs, OH), 2.45 (2H, m, CH2), 1.32 (3H, d, $j=7.07, \mathrm{CH} 3), 1.05$ (3H, t, $j=7.32$, CH3), (ESI, Fig. $\mathrm{S} 4 \dagger)$

Reference: $[\alpha]_{\mathrm{D}}^{25}=+48^{\circ}(c=0.9 \text {, chloroform })^{11}$

$(S)$-2-Hydroxy-hexan-3-one $(2 \mathbf{b}):[\alpha]_{\mathrm{D}}^{25}=+52.0^{\circ} \pm 1.3(c=0.9$, chloroform), $[\alpha]_{\mathrm{D}}^{20}=+55.2^{\circ} \pm 2.5(c=2.5$, chloroform $)$ yellowish oil, $\left({ }^{1} \mathrm{H}-\mathrm{NMR}, 500 \mathrm{MHz}\right) \delta(\mathrm{ppm}): 4.23(1 \mathrm{H}, \mathrm{q}, j=7.08, \mathrm{CH}-\mathrm{OH})$, 3.52 (1H, bs, OH), 2.45 (2H, m, CH2), 1.66 (2H, m, CH2), 1.38 (3H, d, $j=7.08, \mathrm{CH} 3), 0.93(3 \mathrm{H}, \mathrm{t}, j=7.31, \mathrm{CH} 3)$, (ESI, Fig. S5 $\dagger$ )

$$
\text { Reference: }[\alpha]_{\mathrm{D}}^{20}=+57^{\circ}(c=2.5 \text {, chloroform })^{23}
$$

$(S)$-2-Hydroxy-heptan-3-one $(3 \mathbf{b}):[\alpha]_{\mathrm{D}}^{25}=+59.2^{\circ} \pm 1.9(c=0.9$, chloroform) yellow oil, $\left({ }^{1} \mathrm{H}-\mathrm{NMR}, 500 \mathrm{MHz}\right) \delta(\mathrm{ppm}): 4.22(1 \mathrm{H}, \mathrm{q}$, $j=7.09, \mathrm{CH}-\mathrm{OH}$ ), 3.56 (1H, bs, OH), 2.45 (2H, m, CH2), 1.60 (2H, m, CH2), 1.35 (3H, d, $j=7.14, \mathrm{CH} 3), 1.31(2 \mathrm{H}, \mathrm{m}, \mathrm{CH} 2)$, $0.89(3 \mathrm{H}, \mathrm{t}, j=7.35, \mathrm{CH} 3)$, (ESI, Fig. S6 $\dagger$ ).

\section{Absolute configuration of $\alpha$-hydroxy ketones}

The absolute configuration of reaction products was determined via ${ }^{1} \mathrm{H}-\mathrm{NMR}$ analysis of Mosher's esters of the products according to the protocol of Hoye and coworkers (procedure: 1.b). ${ }^{30}$ In this method, chiral alcohols are esterified with both enantiomers of a phenyl substituted chiral acid. Electrostatic shielding effects lead to a shift in the ${ }^{1} \mathrm{H}-\mathrm{NMR}$-spectrum, which can be correlated with the absolute configuration of the analysed alcohol. The reaction was performed in dichloromethane-d $\left({ }^{1} \mathrm{H}\right.$ : $\delta 5.32$ ) on $50 \mu \mathrm{g}$-scale. The synthesis of $(S)$-Mosher's esters of hydroxy ketones was performed by esterification with the $(R)$-MTPA-Cl $((R)-(-)-\alpha$-methoxy- $\alpha$-(trifluoro-methyl)phenylacetyl chloride, Sigma-Aldrich, Germany), while esterification with the $(S)$-MTPA-Cl gives rise to $(R)$-Mosher's esters. The absolute configuration was then determined by comparison of the ${ }^{1} \mathrm{H}-\mathrm{NMR}$ spectra and the chemical shifts of the two diastereomeric esters, and subsequent determination of $\Delta \delta^{S R}$.

\section{Conclusions}

The asymmetric reduction of prochiral diketones with the alcohol dehydrogenase CPCR2 proves to be a fast and efficient method for the synthesis of $(S)$-2-hydroxy alkanones and a good addition to the existing biocatalytic approaches. While lyases are good catalysts for the synthesis of symmetric hydroxy ketones, lipases are suitable for higher molecular weight compounds. Substrate scope and selectivity make the CPCR2 a valuable biocatalyst for the synthesis of asymmetric low molecular weight hydroxy ketones as described in this study, significantly improving the accessibility of this class of chiral compounds by biochemical synthesis.

\section{Acknowledgements}

Deutsche Forschungsgemeinschaft (DFG) is gratefully acknowledged for financial support within research project AN 387/5-1. We also thank the collaborative research network BioNoCo (GRK1166) for scientific support and fruitful discussion.

\section{Notes and references}

1 P. Hoyos, J. V. Sinisterra, F. Molinari, A. R. Alcántara and P. Domínguez de María, Acc. Chem. Res., 2010, 43(2), 288299.

2 A. D. Franklin and C. S. Aurelia, J. Org. Chem., 1987, 52, 955957.

3 R. Hekmatshoar, M. M. Heravi, Y. S. Beheshtiha and F. Faridbod, Monatsh. Chem., 2002, 133, 195-197.

4 R. Hayakawa, T. Sahara and M. Shimizu, Tetrahedron Lett., 2000, 41, 7939-7942.

5 P. Muthupandi and G. Sekar, Tetrahedron: Asymmetry, 2011, 22, 512-517.

6 M. Koprowski, J. Luczak and E. Krawczyk, Tetrahedron, 2006, 62, 12363-12374.

7 T. Hashiyama, K. Morikawa and K. B. Sharpless, J. Org. Chem., 1992, 57, 5067-5068.

8 T. Sun and X. Zhang, Adv. Synth. Catal., 2012, 354, 32113215.

9 O. A. Hamed, A. El-Qisairi, H. Qaseer, E. M. Hamed, P. M. Henry and D. P. Becker, Tetrahedron Lett., 2012, 53, 2699-2701.

10 D. Richardson, T. K. Page, S. Altermann, S. M. Paradine, A. N. French and T. Wirth, Synlett, 2007, 4, 0538-0542.

11 A. N. Martre, G. Mousset, R. Bel-Rhlid and H. Veschambre, Tetrahedron Lett., 1990, 31(18), 2599-2602.

12 M. Müller, D. Gocke and M. Pohl, FEBS J., 2009, 276, 28942904.

13 H. C. Hailes, D. Rother, M. Müller, R. Westphal, J. M. Ward, J. Pleiss, C. Vogel and M. Pohl, FEBS J., 2013, 280, 6374-6394.

14 A. Baykal, S. Chakraborty, A. Dodoo and F. Jordan, Bioorg. Chem., 2006, 34, 380-393.

15 R. Mikolajek, A. C. Spiess, M. Pohl, L. Sylvain and J. Büchs, ChemBioChem, 2007, 8, 1063-1070.

16 R. Mikolajek, A. C. Spiess, M. Pohl and J. Büchs, Biotechnol. Prog., 2009, 25(1), 132-138. 
17 P. Domínguez de María, M. Pohl, D. Gocke, H. Gröger, H. Trauthwein, T. Stillger, L. Walter and M. Müller, Eur. J. Org. Chem., 2007, 2940-2944.

18 M. Beigi, S. Loschonsky, P. Lehwald, V. Brecht, S. L. A. Andrade, F. J. Leeper, W. Hummel and M. Müller, Org. Biomol. Chem., 2013, 11, 252-256.

19 G. Scheid, W. Kuit, E. Ruijter, R. V. A. Orru, E. Henke, U. Bornscheuer and L. A. Wessjohann, Eur. J. Org. Chem., 2004, 1063-1074.

20 O. Bortolini, E. Casanova, G. Fantin, A. Medici, S. Poli and S. Hanau, Tetrahedron: Asymmetry, 1998, 9, 647-651.

21 K. Edegger, W. Stampfer, B. Seisser, K. Faber, S. F. Mayer, R. Oehrlein, A. Hafner and W. Kroutil, Eur. J. Org. Chem., 2006, 1904-1909.

22 R. Bel-Rhlid, A. Fauve and H. Veschambre, J. Org. Chem., 1989, 54, 3223-3224.
23 O. Bortolini, G. Fantin, M. Fogagnolo, P. P. Giovannini, A. Guerrini and A. Medici, J. Org. Chem., 1997, 62, 1854-1856. 24 J. Peters, T. Minuth and M. R. Kula, Biocatalysis, 1993, 8, 3146.

25 J. Peters, T. Minuth and M. R. Kula, Enzyme Microb. Technol., 1993, 15, 950-958.

26 J. Peters, T. Zelinski, T. Minuth and M. R. Kula, Tetrahedron: Asymmetry, 1993, 4(7), 1683-1692.

27 A. Jakoblinnert, M. Bocola, M. Bhattacharjee, S. Steinsiek and M. Boenitz-Dulat, ChemBioChem, 2012, 13(6), 803-809.

28 K. K. Mäkinen, P. L. Mäkinen, S. H. Wilkes, M. E. Bayliss and J. M. Prescott, J. Biol. Chem., 1982, 257(4), 1765-1772.

29 K. Faber, in Biotransformations in Organic Chemistry, Springer, Heidelberg, 2011, pp. 141-144.

30 T. R. Hoye, C. S. Jeffrey and F. M. Shao, Nat. Protoc., 2007, 2(10), 2451-2458. 